\title{
Awareness, Knowledge, Perception and Attitude towards Prescription Medicines Abuse among Medicines Prescribers and Dispensers in Nnewi Nigeria
}

\author{
Prosper Obunikem Uchechukwu Adogu ${ }^{*}$, Ifeoma A. Njelita ${ }^{2}$, Nonye Bibiana Egenti ${ }^{3}$, \\ Chika Florence Ubajaka ${ }^{4}$, Ifeoma A. Modebe ${ }^{5}$ \\ ${ }^{1}$ Consultant Public Health Physician (MBBS, FWACP, FMCPH), Department of Community Medicine, \\ NAU/NAUTH, Nnewi, Nigeria \\ ${ }^{2}$ Consultant Public Health Physician, (MBBS, MPH, FWACP), Department of Community Medicine, NAUTH, \\ Nnewi, Nigeria \\ ${ }^{3}$ Consultant Public Health Physician (MBBS, MPH, FMCPH), Department of Community Medicine, University of \\ Abuja, Abuja, Nigeria \\ ${ }^{4}$ Consultant Public Health Physician (MBBS, FMCPH), Department of Community Medicine, NAU/NAUTH, \\ Nnewi, Nigeria \\ ${ }^{5}$ Consultant Public Health Physician (MBBS, FWACP), Department of Community Medicine, NAU/NAUTH, \\ Nnewi, Nigeria \\ Email: ${ }^{*}$ prosuperhealth50@gmail.com, bright.ifechukwu@gmail.com
}

Received 9 April 2015; accepted 19 May 2015; published 22 May 2015

Copyright (C) 2015 by authors and Scientific Research Publishing Inc.

This work is licensed under the Creative Commons Attribution International License (CC BY).

http://creativecommons.org/licenses/by/4.0/

(c) (i) Open Access

\begin{abstract}
Background: Abuse of medicines is becoming a serious problem in many parts of the world, with negative consequences ranging from addiction, psychosis, cardiovascular complications, and premature deaths from unintentional overdose. Objectives: The objective of this study is to assess awareness, knowledge, perception and attitudes toward the abuse of prescription medicines (PM) among medicines prescribers and dispensers in Nigeria. Design and Participants: A descriptive cross-sectional study was carried out among pharmacists, other pharmacy staff in retail pharmacies, licensed patent medicines vendors (chemical sellers), and medical doctors in Nnewi, Nigeria. Data were collected through self-completed questionnaire supervised by trained research assistants, between December 2013 and April 2014. Three hundred and seventy-five participants were recruited for this study. Data Analysis: The Statistical Package for the Social Sciences (SPSS) version 17 for windows was used for data analysis. Bivariate and multivariate analyses were carried
\end{abstract}

${ }^{*}$ Corresponding author.

How to cite this paper: Adogu, P.O.U., Njelita, I.A., Egenti, N.B., Ubajaka, C.F. and Modebe, I.A. (2015) Awareness, Knowledge, Perception and Attitude towards Prescription Medicines Abuse among Medicines Prescribers and Dispensers in Nnewi Nigeria. Pharmacology \& Pharmacy, 6, 254-266. http://dx.doi.org/10.4236/pp.2015.65028 
out to evaluate differences and associations based on selected variables. Results: The perception was high 294 (78.4\%) among respondents that PM abuse was a problem in the community. Knowledge of health problems associated with PM abuse was also high at $226(60.3 \%)$. However the attitude of the respondents towards early detection of PM abuse among their patients/clients was discouraging. Education, educational status, work status and gender significantly predict good knowledge and positive attitude about PM abuse. Conclusion: Findings from this study will assist health authorities to formulate appropriate health promotion interventions to control and prevent abuse of prescription medicines. Actions directed at early intervention, capacity building, education, public health initiatives and law enforcements will hopefully curb the menace of PM abuse in Nnewi, Nigeria.

\section{Keywords}

Prescription Medicine Abuse, Knowledge, Attitude, Nnewi, Nigeria

\section{Introduction}

Abuse of medicines is becoming a serious public health problem in many parts of the world. Prescription medicine (PM) abuse is described as using a medication without prescription, taking medication in a higher quantity or in another manner than prescribed, or using it for another purpose than prescribed [1]. This includes prescription medicines such as stimulants (e.g. amphetamines), anxiolytics (e.g. benzodiazepines), opioid analgesics as well as over-the-counter medicines such as cough and cold medicines abused for psychoactive effects.

According to the Centers for Disease Control (CDC), the percent of people taking at least one prescription drug increased by 50 percent between the years of 2007 and 2010 [2]. While the abuse of illicit drugs goes down, more and more people begin to abuse "legal" prescription medicines. This is a fast-growing trend in the United States [3] and developing countries such as Nigeria [4]. Even more alarming is the fact that young people aged 15 to 24 years is the fastest growing demographic of prescription drug abuse.

Prescription drugs are easy to abuse because they are so easy to find and not just getting them from the doctor. The National Institute on Drug Abuse reports that most people who abuse prescription drugs get them from relatives or friends. This can be done as people share their prescriptions with others—or even as abusers steal them from medicine cabinets or purses [3] [5].

Another factor that contributes to prescription medicine abuse is the fact that so many people think that because medications are legal, they are safe. Unfortunately, this is not true, despite the perception. Prescription drugs are only safely used by those to whom they have been prescribed, and only when following directions. In fact, these so-called "legal" drugs are not actually legal when they are not taken according to physician instructions [6].

Individuals abuse prescription medicines for various reasons that may include: in order to get high; as selfmedication for anxiety, pain, or sleep problems; or to enhance cognition [7]. It could also be used as secondary drug among those who abuse alcohol and illicit drugs [8]. However, these reasons/purposes may vary by gender, age and other factors. Since medications are usually consumed at high doses, the abuse of opioids, central nervous system depressants, and stimulants can lead to addiction. Other negative consequences of prescription medicine abuse include psychosis, seizures, cardiovascular complications, unintentional overdose and premature deaths from respiratory depression and drug interactions [7].

Pharmacists, other pharmacy staff in retail pharmacies, licensed patent medicines vendors (chemical sellers), and medical doctors are important stakeholders in the prescribing and dispensing of medicines. Substance abusers obtain prescription medicines through over-prescribing by a physician, obtaining multiple prescriptions from different physicians, stealing from homes and pharmacies/patent medicines vendors (chemical) shops, obtaining medicines from family and friends, re-purchasing medicines from patients leaving pharmacies/chemical shops, and through other illegal means [9] [10].

Therefore, apart from physicians who prescribe medicines, pharmacists, other pharmacy staff in retail pharmacies involved in the dispensing of medicines, and licensed proprietary patent medicines vendors (PPMVs) are important stakeholders in substance abuse prevention. It is important that they are aware of this problem and 
should have sufficient knowledge to identify medication abuse. They also play crucial role in educating individuals with substance abuse problems. For example, a study in the US [11] found that pharmacists who received substance abuse and addiction training in pharmacy schools were more comfortable and confident in providing counseling to patients and referring patients to drug abuse treatment.

Abuse of medicines is a public health problem in many parts of the world [12]. Therefore a comprehensive effort involving relevant stakeholders in the prescription and distribution of medicines is required to prevent misuse of medicines from becoming a serious problem in Nigeria. To the best of our knowledge, no research study involving relevant stakeholders in the prescription and distribution of medicines has been carried out in any single study in Nigeria. The results of this study will provide valuable information, for planning health promotion and for developing preventive measures against abuse and misuse of medicines for non-medicinal purposes and to promote the practice of rational use of medicines.

The objectives of this study include assessing awareness, knowledge, perception and attitudes of prescribers and dispensers of medicines toward the abuse of PMs in Nnewi, Nigeria and determining the respondents' socio-demographic predictors of their knowledge and attitude towards PM abuse.

\section{Material and Methods}

\subsection{Study Area}

Nnewi is the second largest town in Anambra State, Nigeria located east of the river Niger and about $22 \mathrm{~km}$ southeast of Onitsha and within the tropical rain forest region of Nigeria. Nnewi, as a historical town has many cultural events adorned with festivities and monuments. The town has several private and government-owned health facilities including, health posts, primary health centers and a teaching hospital. Others include licensed private hospitals, clinics, pharmacy shops and proprietary patent medicine vendor (PPMV) stores. These health facilities are manned by health care practitioners including prescribers (mainly doctors) and dispensers (mainly pharmacists, other pharmacy staff, PPMVs etc.).

\subsection{Study Design and Sample Selection}

A descriptive cross-sectional study was carried out among 375 respondents made up of: 40 pharmacists, 85 pharmacy staff in retail pharmacies, 67 licensed patent medicines vendors (PPMVs) also called chemical sellers, 100 other drug handlers like nurses and laboratory staff, and 83 medical doctors in Nnewi, Nigeria. Pharmacists, and medical doctors were recruited through their professional associations while licensed chemical sellers were recruited using a list obtained from the Pharmacists Council of Nigeria (i.e. Government agency responsible for regulation of Pharmacy Practice in Nigeria). The other pharmacy staff were recruited from the pharmacies selected for the study. From each group, participants were selected using simple random sampling technique from a sampling frame of members. The selected participants were identified and approached to complete the questionnaires.

\subsection{Data Collection}

Data was collected through self-completed questionnaire supervised by trained research assistants. Contact was made with the leaders of the hospitals; pharmacies (sts)', medical doctors' and licensed patent medicines vendors' (PMVs') association to gain their support and to mobilize their members to self-complete the questionnaires, which were distributed at their various places of practice during one of their regular meetings. The research was conducted between December 2013 and April 2014. To encourage honest responses, participants were required to disclose their names and other personal identifiers on the questionnaire.

\subsection{Sample Size Calculation}

Using Tabachnick and Fidell (2007) sample size estimation for regression analysis as stated by Pallant [13], and assuming $10 \%$ attrition rate to further improve the validity of this study, 375 respondents were recruited.

\subsection{The Questionnaire}

Items on the questionnaire included socio-demographic variables such as age and gender, and questions to assess 
awareness, knowledge, perception and attitudes towards abuse of medicines.

\subsection{Data Analysis}

Data was analyzed using the Statistical Package for Social Sciences (SPSS) version 17 for windows. Results were presented as frequencies, percentages and summary statistics such as mean and standard deviation. Bivariate and multivariate analyses were carried out to evaluate differences and associations between selected variables.

\section{Result Tables and Figures}

Table 1 shows that the predominant age group among the respondents is 20 - 30 years (44.8\%), while the 51 60 years age group made up only $3.7 \%$ of the respondents. The mean age of respondents was $33.2 \pm 8.9$ years, while the median age was 35 years. There were 83 (22.1\%) medical doctors and 40 (10.7\%) pharmacists among the respondents. The rest were other drug handlers like PPMVs, pharmacy technicians etc. A large proportion, 147 (39.2\%) had attained at least post-secondary education lower than university degree and majority 198 (52.8\%) had acquired 2 - 5 years working experience.

Figure 1 depicts that majority 294 (78.4\%) of the respondents perceive PM abuse as a problem while 79 (21.1\%) were not sure of their perception.

Table 2 shows that $17.6 \%$ of the respondents cited frequent unscheduled visits/consultations by some patients to request for refills of prescription medicines" as noticeable evidence of PM abuse among them. Similarly $17.1 \%$ cited the fact that some patients regularly claim to have lost their prescription forms and request for replacement" as another evidence. Also $16.5 \%$ of the doctor respondents believe that when some patients consume prescription medicines much faster than indicated, it is a sign that they indulge in PM abuse. On the other hand, 25.3\% of pharmacists/PPMVs etc believed that when some customers buy prescription medicines more frequently than normal, it is clear evidence that they indulge in PM abuse. About $19.7 \%$ of this group also stated that if some customers came to purchase the same type of prescription medicine with multiple prescriptions made by the same or different doctors, then that is an indication that they indulge in PM abuse.

Figure 2 is a depiction of knowledge about health problems associated with PM abuse. A large number of the respondents (226; 60.3\%) associated all the listed health problems with PM abuse. One hundred and fifteen (30.7\%) linked addiction to PM abuse while 70 (18.7\%) associated it with accidental overdose.

Figure 3 depicts about $21.1 \%$ of respondents are aware that self-medication for emotional or physical pain is a non-medical reason for which people need prescription medicine; whereas $18.4 \%$ said people use PM to induce sleep. About $72.5 \%$ are aware that all the non-medical reasons listed are reasons for PM abuse.

Table 3 shows that significantly higher proportion of doctors than other health workers rate their knowledge of PM abuse as adequate, $\mathrm{p}<0.005$.

Table 4 shows that significantly higher proportion of doctors (85.5\%) than non-doctors $(48.9 \%)$ have received any training on drug and PM abuse $(\mathrm{p}<0.01)$. Similarly, markedly higher proportion of doctors $(90.4 \%)$

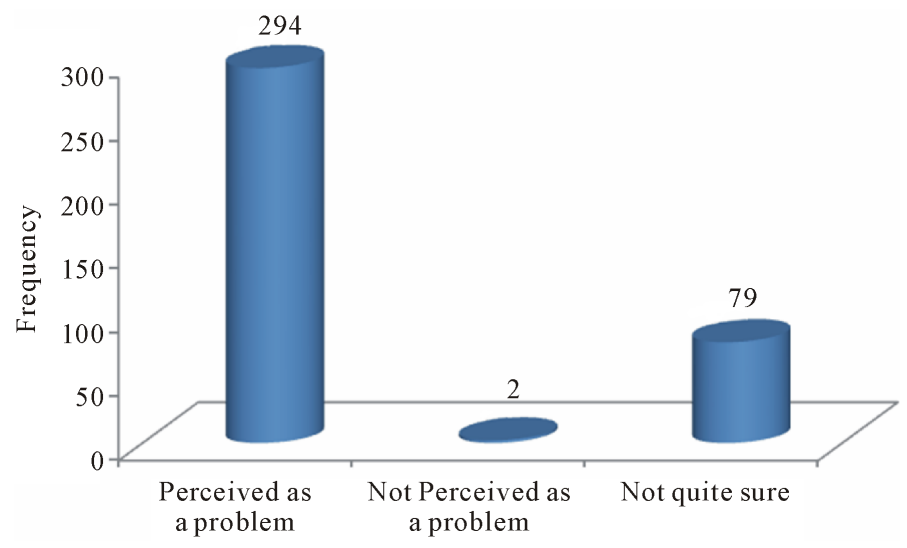

Figure 1. Perception of prescription medicine abuse as a problem in the community. 
Table 1. Socio-demographic variables of respondents.

\begin{tabular}{|c|c|c|}
\hline Socio-demographic variables & Frequency & Percent \\
\hline \multicolumn{3}{|l|}{ Age group (Years) } \\
\hline$<20$ & 10 & 2.7 \\
\hline $20-30$ & 168 & 44.8 \\
\hline $31-40$ & 127 & 33.9 \\
\hline $41-50$ & 56 & 14.9 \\
\hline $51-60$ & 14 & 3.7 \\
\hline Total & 375 & 100 \\
\hline Mean age \pm SD & $33.2 \pm 8.9$ Years & \\
\hline \multicolumn{3}{|l|}{ Gender } \\
\hline Male & 176 & 46.9 \\
\hline Female & 199 & 53.1 \\
\hline Total & 375 & 100 \\
\hline \multicolumn{3}{|l|}{ Occupation } \\
\hline Pharmacist & 40 & 10.7 \\
\hline Pharmacy technicians & 36 & 9.6 \\
\hline Trained Pharmacy assistants & 49 & 13.0 \\
\hline Doctors & 83 & 22.1 \\
\hline PPMV & 67 & 17.9 \\
\hline Other drug handlers (nurses, laboratory attendants) & 100 & 26.7 \\
\hline Total & 375 & 100 \\
\hline \multicolumn{3}{|l|}{ Educational level } \\
\hline Secondary education or less & 49 & 13.0 \\
\hline Post-secondary qualification lower than bachelor's degree & 147 & 39.2 \\
\hline Bachelor's degree & 145 & 38.7 \\
\hline Master’s degree & 18 & 4.8 \\
\hline PhD degree & 16 & 4.3 \\
\hline Total & 375 & 100 \\
\hline \multicolumn{3}{|l|}{ Year of experience (Years) } \\
\hline$\leq 1$ & 64 & 17.1 \\
\hline $2-5$ & 198 & 52.8 \\
\hline $6-10$ & 48 & 12.8 \\
\hline $11-20$ & 43 & 11.5 \\
\hline $21-30$ & 14 & 3.7 \\
\hline $31-35$ & 8 & 2.1 \\
\hline Total & 375 & 100 \\
\hline Mean year of experience \pm SD & $6.3 \pm 6.9$ years & \\
\hline \multicolumn{3}{|l|}{ Employment status } \\
\hline Self employed & 139 & 37.1 \\
\hline Employee (of hospital, pharmacy or PPMV) & 236 & 62.9 \\
\hline Total & 375 & 100 \\
\hline
\end{tabular}


Table 2. Respondents’ awareness of early evidence of PM abuse by clients.

\begin{tabular}{|c|c|}
\hline Evidence of abuse of PM noticed by doctors & Number (\%) of doctors who are aware \\
\hline $\begin{array}{l}\text { Some patients were receiving prescription for the same prescription } \\
\text { medicine from other undisclosed doctors }\end{array}$ & $(7.5)$ \\
\hline $\begin{array}{l}\text { Frequent unscheduled visits/consultations by some patients } \\
\text { to request for refills of prescription medicines }\end{array}$ & $(17.6)$ \\
\hline $\begin{array}{l}\text { Some patients regularly claim to have lost their prescription } \\
\text { forms and request for replacement }\end{array}$ & $(17.1)$ \\
\hline Some patients consume prescription medicines much faster than indicated & $(16.5)$ \\
\hline Evidence of abuse of PM noticed by pharmacists/PPMVs & $\begin{array}{l}\text { Number (\%) of pharmacists/PPMVs } \\
\text { etc who are aware }\end{array}$ \\
\hline Some customers were buying prescription medicines more frequently than normal & $(25.3)$ \\
\hline $\begin{array}{l}\text { Some customers came to purchase the same type of prescription medicine } \\
\text { with multiple prescriptions made by the same or different doctors }\end{array}$ & $(19.7)$ \\
\hline Some customers presented forged or altered prescription forms & $(11.2)$ \\
\hline $\begin{array}{c}\text { Some customers were buying large quantities of cough medicines } \\
\text { or cold medicines at a single purchase }\end{array}$ & $(7.5)$ \\
\hline $\begin{array}{l}\text { Some customers were buying cough medicines or cold } \\
\text { medicines too frequently than normal }\end{array}$ & $(16.5)$ \\
\hline
\end{tabular}

Table 3. Rating of knowledge of PM abuse and drug addiction in general.

\begin{tabular}{|c|c|c|c|c|}
\hline \multirow[b]{2}{*}{ Knowledge Rating } & \multicolumn{2}{|c|}{ Number (\%) of respondents } & \multirow[b]{2}{*}{$X^{2}$} & \multirow[b]{2}{*}{$\mathrm{p}$-value } \\
\hline & $\begin{array}{l}\text { Doctors } \\
\text { No (\%) }\end{array}$ & $\begin{array}{c}\text { Other respondents } \\
\text { No (\%) }\end{array}$ & & \\
\hline Very inadequate & $6(7.2)$ & $65(22.3)$ & \multirow{6}{*}{17.6} & \multirow{6}{*}{$\mathrm{p}<0.005$} \\
\hline Inadequate & $6(7.2)$ & $58(19.9)$ & & \\
\hline Unsure & $6(7.2)$ & $44(15.1)$ & & \\
\hline Adequate & $40(48.2)$ & $120(41)$ & & \\
\hline Very adequate & $7(8.4)$ & $35(12)$ & & \\
\hline Total & 83 & 292 & & \\
\hline
\end{tabular}

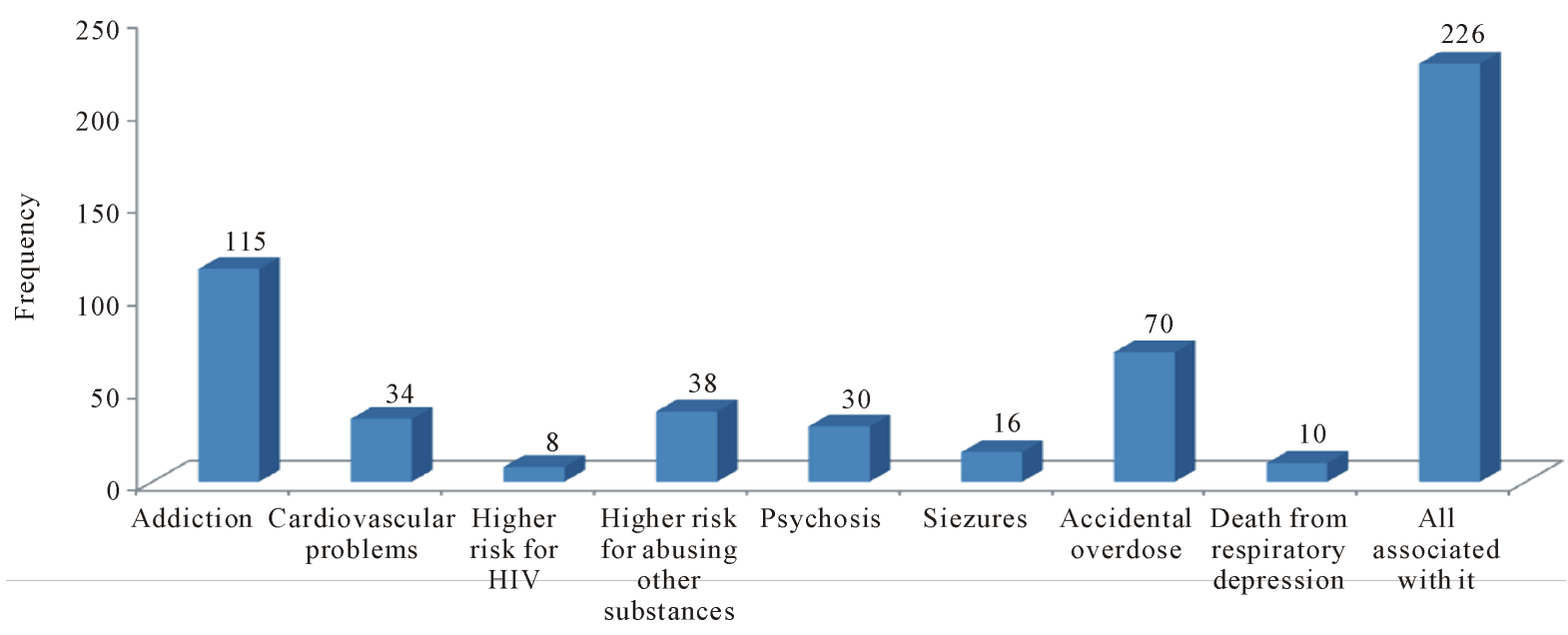

Figure 2. Respondents' knowledge of health problems associated with abuse of PM. 


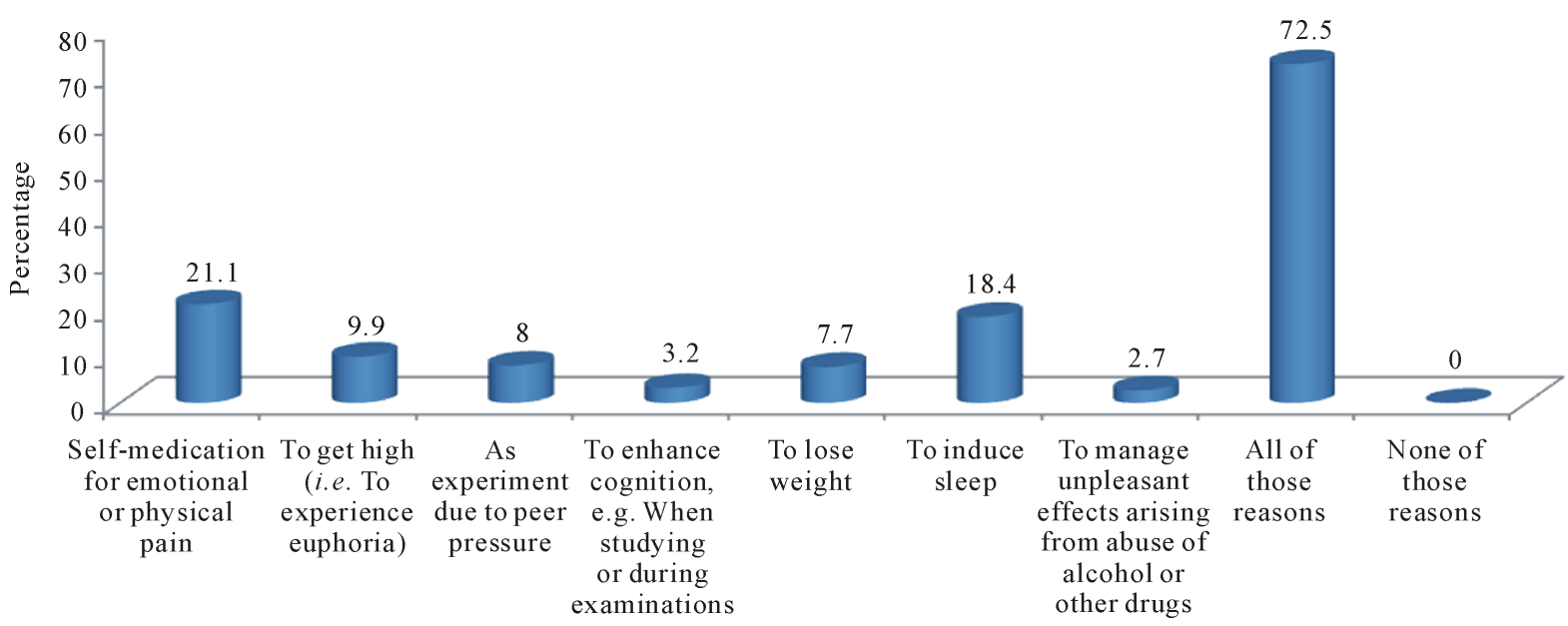

Figure 3. Awareness of non-medical purposes for which people need prescription medicine.

Table 4. Attitude of respondents towards prescription medicine abuse.

\begin{tabular}{|c|c|c|c|c|}
\hline \multirow[b]{2}{*}{ Attitude items } & \multicolumn{2}{|c|}{ Number (\%) of respondents } & \multirow{2}{*}{$\mathrm{X}^{2}$} & \multirow[b]{2}{*}{ p-value } \\
\hline & $\begin{array}{l}\text { Doctors } \\
\text { No (\%) }\end{array}$ & $\begin{array}{c}\text { Other respondents } \\
\text { No (\%) }\end{array}$ & & \\
\hline \multicolumn{5}{|l|}{ Perception of role in prevention of PM abuse } \\
\hline Very unimportant/Unimportant & $11(13.3)$ & $58(19.9)$ & \multirow{4}{*}{4.51} & \multirow{4}{*}{$\mathrm{p}>0.05$} \\
\hline Unsure & $6(4.8)$ & $8(2.7)$ & & \\
\hline Important/Very important & $66(81.9)$ & $226(77.4)$ & & \\
\hline Total & $83(100)$ & $292(100)$ & & \\
\hline \multicolumn{5}{|c|}{ Received any training on DA including PM abuse } \\
\hline Yes & $71(85.5)$ & $143(48.9)$ & \multirow{3}{*}{30.1} & \multirow{3}{*}{$\mathrm{p}<0.01^{*}$} \\
\hline No & $12(14.5)$ & $149(51)$ & & \\
\hline Total & $83(100)$ & $292(100)$ & & \\
\hline \multicolumn{5}{|c|}{ Willing to attend a training session on DA including PM abuse } \\
\hline Yes & $70(84.3)$ & $258(88.4)$ & \multirow{4}{*}{0.97} & \multirow{4}{*}{$\mathrm{p}>0.5$} \\
\hline No & $13(15.7)$ & $34(11.6)$ & & \\
\hline Not sure & 0 & 0 & & \\
\hline Total & $83(100)$ & $292(100)$ & & \\
\hline \multicolumn{5}{|l|}{ Ever spoken to a client about abuse of PM } \\
\hline Yes & $69(83.1)$ & $220(75.3)$ & \multirow{3}{*}{3.05} & \multirow{3}{*}{$\mathrm{p}>0.05$} \\
\hline No my clients did not need it & $8(9.6)$ & $34(11.6)$ & & \\
\hline No even though my clients need it & $6(7.2)$ & $38(13)$ & & \\
\hline \multicolumn{5}{|c|}{ Willingness to provide counseling to clients about PM abuse } \\
\hline Yes & $75(90.4)$ & 204 (69.9) & \multirow{3}{*}{12.8} & \multirow{3}{*}{$\mathrm{p}<0.025^{*}$} \\
\hline No & $8(9.6)$ & $88(30.1)$ & & \\
\hline Not sure & 0 & 0 & & \\
\hline \multicolumn{5}{|c|}{ Willingness to refer PM abusers for treatment in future } \\
\hline Yes & $64(77.1)$ & $250(85.6)$ & \multirow{3}{*}{26.5} & \multirow{3}{*}{$\mathrm{p}<0.01^{*}$} \\
\hline No & 13 (15.7) & $7(2.4)$ & & \\
\hline Not sure & $6(7.2)$ & 35 (12) & & \\
\hline
\end{tabular}


than non-doctors (69.9\%) are willing to provide counseling services to clients about PM abuse ( $<<0.025)$. Furthermore, significantly higher proportion of non-doctors (85.6\%) than doctors $(77.1 \%)$ expressed willingness to refer PM abusers for treatment in future $(\mathrm{p}<0.01)$.

Figure 4 is a picture of comparative analysis between doctors and other respondents for each of the identified barriers to counseling clients against PM abuse. Significantly higher proportion of doctors (27.7\%) than the other respondents (4.5\%) identified lack of time as s barrier to counseling clients about PM abuse $(\mathrm{p}<0.01)$. Conversely, markedly higher proportion of non-doctor responders (45.2\%) than the doctor responders (12\%) said the clients ignore the advice given to them $(\mathrm{p}<0.01)$.

Furthermore, significantly higher proportion of doctors (44.5\%) than other responders (25.3\%) felt they had no barriers to counseling of their clients against PM abuse $(\mathrm{p}<0.02)$. Also markedly higher proportion $(9.9 \%)$ of the non-doctor respondents than doctors (2.4\%) said they did not possess the necessary skills to counsel clients $(\mathrm{p}<0.01)$.

In Table 5, occupation as a doctor is predictive of good knowledge and attitude towards PM abuse: adjusted OR of 1.90 (1.23 - 4.13); $<<0.005$ and adjusted OR of 1.39 (1.17 - 4.11); $\mathrm{p}<0.01$ respectively. The same is applicable to the occupation as pharmacist: adjusted ORs of $2.11(1.21$ - 3.24); $\mathrm{p}<0.005$ and 1.93 (1.71 - 3.84); $\mathrm{p}<0.01$, respectively. Moreover, education at the bachelor's degree level upwards is significantly predictive of good knowledge about PM abuse: adjusted ORs of 1.15 (0.59 - 4.14); $<<0.01,1.06$ (0.61 - 3.95); $\mathrm{p}<0.01$ and 1.53 (0.46 - 3.72); $\mathrm{p}<0.04$ respectively. Responders who have worked for $2-5$ years and $6-10$ years respectively are significantly predictive of knowledge of PM abuse: adjusted ORs of 1.21 (0.75 - 4.53); p < 0.001 and 1.10 (0.91 - 3.87); $\mathrm{p}<0.01$ respectively. Those who have worked for $2-5$ years, $6-10$ years and $31-35$ years are also predictive of good attitude towards PM abuse: adjusted ORs of 1.93 (1.15 - 3.65); p < 0.01, 1.32 (1.12 3.83); $\mathrm{p}<0.01$ and 1.88 (1.50 - 3.61) respectively. Age, gender and employment status are also significantly predictive of PM abuse among the respondents.

\section{Discussion}

Prescription medicine abuse has assumed epidemic proportions among patients and clients in Nigeria [1]. Doctors, Pharmacists and other medicine handlers and prescribers have pivotal roles to play in controlling and standardizing the use of prescription medicine among their clients and patients. Therefore their knowledge, perception and attitudes towards the problem are of utmost interest in the search for a permanent solution.

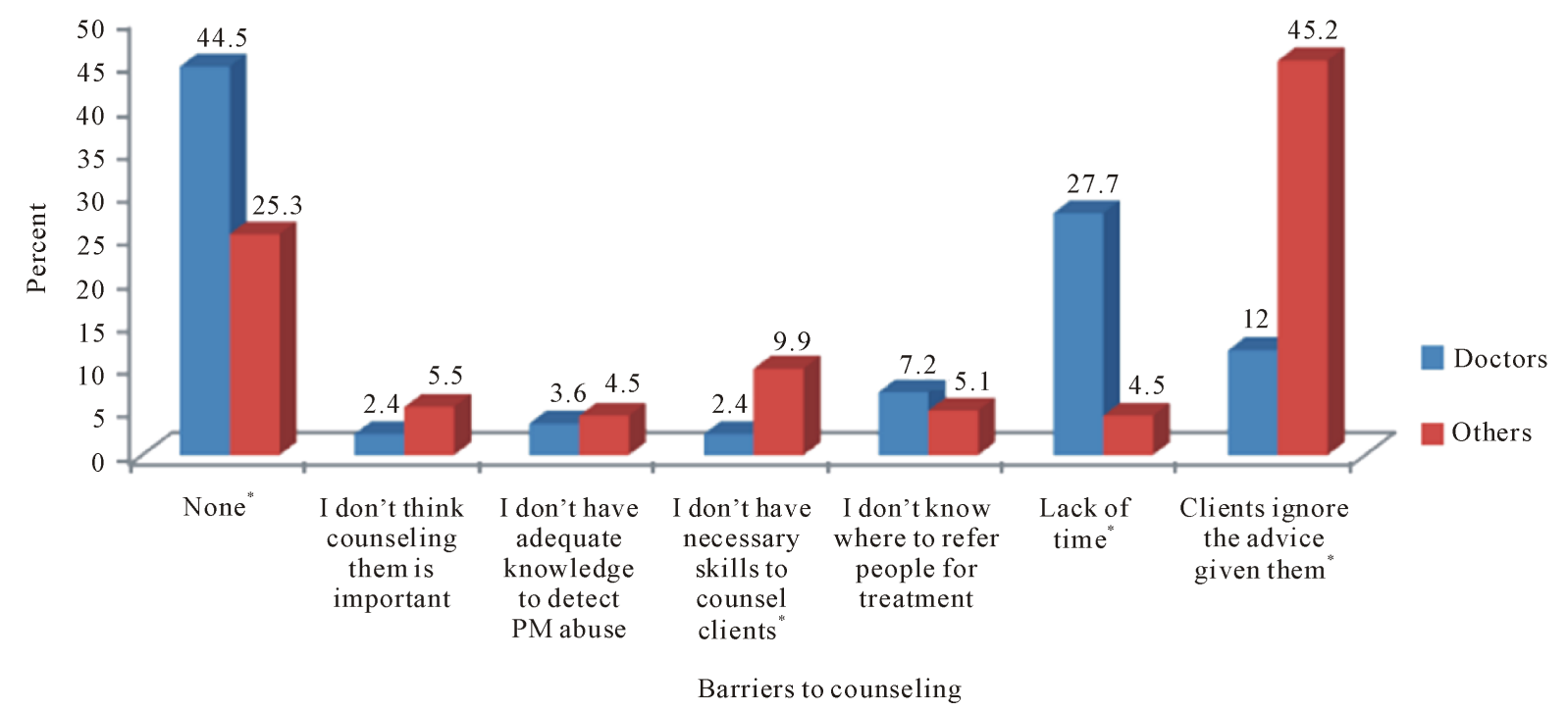

Figure 4. Barriers to counseling of clients about abuse of PM. NB: * significant differences; "“Lack of time” significant difference between doctors and others at $\mathrm{p}<0.01(\mathrm{z}=5.57)$; “"Clients ignore the advice given them" significant difference between doctors and others at $\mathrm{p}<0.01(\mathrm{z}=5.3)$; "No barriers to counseling" significant difference between doctors and others at $\mathrm{p}<0.02,(\mathrm{z}=3.37)$; “"Lack of necessary skills to counsel clients" significant difference between doctors and others at $p<0.01(z=5)$. 
Table 5. Socio-demographic predictors of good knowledge and attitude towards PM abuse.

\begin{tabular}{|c|c|c|c|}
\hline Socio-demographic characteristics that predict good knowledge ${ }^{\dagger}$ & Crude OR & Adjusted OR (95\% CI) & p-value \\
\hline \multicolumn{4}{|l|}{ Occupation } \\
\hline Pharmacist & 3.40 & $2.11(1.21-3.24)$ & 0.005 \\
\hline Pharmacy technicians & 1.37 & $0.87(0.46-2.73)$ & 0.17 \\
\hline Trained Pharmacy assistants & 1.82 & $0.98(0.37-2.19)$ & 0.07 \\
\hline Doctors & 3.21 & $1.90(1.23-4.13)$ & 0.005 \\
\hline \multicolumn{4}{|l|}{ *PPMV } \\
\hline \multicolumn{4}{|l|}{ Other drug handlers (nurses, laboratory attendants) } \\
\hline \multicolumn{4}{|l|}{ Educational level } \\
\hline *Secondary education or less & 1.29 & & \\
\hline Post-secondary qualification lower than bachelor's degree & 1.53 & $0.34(0.19-2.02)$ & 0.13 \\
\hline Bachelor’s degree & 2.74 & $1.15(0.59-4.14)$ & 0.01 \\
\hline Master’s degree & 2.32 & $1.06(0.61-3.95)$ & 0.01 \\
\hline PhD degree & 2.07 & $1.53(0.46-3.72)$ & 0.04 \\
\hline \multicolumn{4}{|l|}{ Year of experience (Years) } \\
\hline${ }^{*} \leq 1$ & 1.10 & & \\
\hline $2-5$ & 1.31 & $0.90(0.47-2.10)$ & 0.10 \\
\hline $6-10$ & 3.42 & $1.21(0.75-4.53)$ & 0.005 \\
\hline $11-20$ & 2.36 & $1.10(0.91-3.87)$ & 0.01 \\
\hline $21-30$ & 1.41 & $1.25(1.01-2.00)$ & 0.16 \\
\hline $31-35$ & 1.83 & $1.42(1.28-2.93)$ & 0.07 \\
\hline Socio-demographic characteristics that predict positive Attitude & Crude OR & Adjusted OR (95\% CI) & p-value \\
\hline \multicolumn{4}{|l|}{ Age group (Years) } \\
\hline${ }^{*}<20$ & 1.21 & & \\
\hline $20-40$ & 3.64 & $1.03(0.86-4.26)$ & 0.01 \\
\hline $41-60$ & 2.71 & $1.18(1.01-3.37)$ & 0.01 \\
\hline \multicolumn{4}{|l|}{ Gender } \\
\hline "Male & 1.75 & & \\
\hline Female & 2.81 & $1.31(0.91-3.76)$ & 0.01 \\
\hline \multicolumn{4}{|l|}{ Employment status } \\
\hline *Self employed & 1.12 & & \\
\hline Employee (of hospital, pharmacy or PPMV) & 2.78 & $1.25(0.79-3.38)$ & 0.01 \\
\hline \multicolumn{4}{|l|}{ Year of experience (Years) } \\
\hline${ }^{*}<1$ & 1.20 & & \\
\hline $2-5$ & 1.43 & $1.01(0.72-2.11)$ & 0.15 \\
\hline $6-10$ & 2.77 & $1.93(1.15-3.65)$ & 0.01 \\
\hline $11-20$ & 2.65 & $1.32(1.12-3.83)$ & 0.01 \\
\hline $21-30$ & 1.98 & $1.41(1.23-2.71)$ & 0.05 \\
\hline $31-35$ & 2.93 & $1.88(1.50-3.61)$ & 0.01 \\
\hline \multicolumn{4}{|l|}{ Occupation } \\
\hline Pharmacist & 2.84 & $1.93(1.71-3.84)$ & 0.01 \\
\hline Pharmacy technicians & 1.67 & $1.21(1.13-2.50)$ & 0.10 \\
\hline Trained Pharmacy assistants & 1.83 & $1.47(1.21-2.84)$ & 0.07 \\
\hline Doctors & 2.71 & $1.39(1.17-4.11)$ & 0.01 \\
\hline "PPMV & 1.16 & & \\
\hline Other drug handlers (nurses, laboratory attendants) & 1.92 & $1.48(1.12-2.23)$ & 0.06 \\
\hline
\end{tabular}

${ }^{\dagger}$ Good knowledge is given by knowledge of all the items plotted in Figure 2 and Figure 3; ${ }^{\dagger \dagger}$ Positive attitude here is given by a combination of 4 or more of the items in Table 4. 
The large proportion (78.2\%) of respondents who perceive PM abuse as a problem in the community is not entirely surprising considering their impressive academic credentials-only $13 \%$ possess secondary educational qualification or less, the rest have post-secondary, masters and even doctorate degrees. The high perception of PM abuse was also reported among health workers in another study [6]. The same explanation can be offered for their impressive knowledge of health problems associated with PM abuse. Unfortunately, this has not translated into desired state of alertness, suspicion and positive attitudes necessary to galvanize effective control mechanisms to stem the tide of the PM abuse in our communities. For example the respondents have displayed a generally poor index of suspicion and awareness towards the early signs of PM abuse by their clients. Only 7.5\% of doctor respondents could pinpoint the fact that "when patients received prescription for the same prescription medicine from other undisclosed doctors” that is early evidence of PM abuse. Equally among the non-doctor respondents only 7.5\% could link to early evidence of PM abuse, the situation whereby their customers "buy large quantities of cough medicines or cold medicines at a single purchase”.

It takes a high index of suspicion by all health workers to recognize early signs of PM abuse among their clients. Prescription drug abuse does come with warning signs. Some of these include dramatic changes in behavior like withdrawal from one's social life, dramatic drops in grades at school, or in performance at work, abrupt mood swings on a regular basis, increased annoyance, secrecy, paranoia and irritability [14]. Others include dramatic changes in appearance; sudden weight loss proceeded by loss of appetite. However, if there is a change in grooming and hygiene, that can also be a sign of prescription medicine abuse. Prescription drug addicts eventually stop taking proper care of themselves [14]. One may notice that a friend, relative or child stops bathing as often, or pays little attention to the neatness and cleanliness of clothes and hair [14]. Also if someone has been taking a prescription drug for a long time, without seeming to improve in condition, it could be a sign of prescription drug abuse. Someone addicted to prescription drugs may fake symptoms in order to continue receiving medication. Another indication is if the user keeps switching doctors. This may be a ploy to get extra prescriptions [14]. Another warning sign is an increase in the amount of the prescription drug taken [14].

It is worrisome that the respondents in this study are not very confident about their knowledge of PM abuse and drug abuse in general. Every health worker should be able to recognize the earliest sign of PM abuse bearing in mind though, that the presence of just one sign of prescription drug abuse is unlikely to indicate a problem. Many of the above signs also indicate other problems that may not be related. The key is to look for more than one indication of possible prescription drug abuse [15]. The more the indications of prescription drug abuse that are manifest, the higher the likelihood that there really is a problem. Equally important indicator of PM abuse is the presence of drug related paraphernalia such as more empty bottles in trash cans, always carrying about a bottle of pills [15]. Also, the observant health worker should keep track of own stock of medications. If the stock seems to be depleting at a faster than normal pace, it could mean that someone is stealing them for "recreational" purposes-or even to sell to others. Furthermore, a client who is always looking for money which (could merely indicate that one has fallen on hard times), may also be exhibiting another sign of prescription drug abuse [16]. Addicts need to pay for more drugs. This takes money. If someone is selling his or her treasured possessions, stealing or always asking for money to buy vague things that they "need", it could be an indication of a prescription drug addiction [16].

A comparative analysis of the attitude of the respondents to PM abuse reveals that significantly higher proportion of doctors than non-doctors received training on drug abuse including PM abuse. This has apparently led to a higher proportion of doctors expressing greater willingness to offer counseling services to their clients about PM abuse. This finding underscores the need for regular training of all prescribers and dispensers on PM abuse. Furthermore, the finding that the female gender significantly predicts positive attitude to PM abuse seems to agree with the belief that females are more compassionate and more likely to notice minute details than men [17].

The barriers to counseling of clients against PM abuse needs special mention. It is instructive to note that markedly higher proportion of non-doctor responders than doctors said that the clients ignore the advice given to them concerning PM abuse. Effort should be directed at public enlightenment with the message that non-doctors (dispensers) also possess the necessary counseling skills that should be adhered to. Also the non-doctor health workers should be encouraged to undergo regular training on PM abuse in order to sharpen their counseling skill necessary to command the respect of the clients. This becomes even more pertinent in view of the belief by some non-doctors in this study that they did not possess the necessary skills to counsel clients. On the other hand, a significantly higher proportion of doctors than non-doctors cited "lack of time" as a barrier to counseling. It 
has become an accepted norm that clinicians hardly have time to spare for counseling order than that for quick clinical appraisal and prescription of drugs [18]. This attitude adversely affects good patient-clinician relationship which has both emotional and informational components [19].

An exploration of the socio-demographic predictors of good knowledge and attitude towards PM abuse reveals that occupations as doctor and pharmacist are predictive of good knowledge and positive attitude towards PM abuse. These are well trained professionals who must have received some formal kinds of didactic instructions on the subject matter in course of their formal training [20]. However, the poor doctor/patient and even worse pharmacist/patient ratios [21] [22] make it imperative that other health workers must also possess desired knowledge and attitude towards PM abuse through regular informal training sessions. This will put them in good stead to also effectively participate in this fight against PM abuse. Similar regular informal training should also be given to health workers who possess below bachelor's degree qualifications as this study has shown that only respondents with bachelors' degree and above have significantly predicted good knowledge and positive attitude towards PM abuse.

Employment status is also significantly predictive of PM abuse among the respondents. Government workers stick to the rules regarding the right knowledge and attitude for them to keep their jobs. On the other hand, the self-employed private practitioner gives account of his work activities to nobody but himself and enjoys the liberty to unfortunately practice his trade according to his whims and caprices. This must be discouraged and in order to stem the tide of PM abuse, government should insist on the same standard of practice for both public and private enterprises.

\section{Conclusion}

Prescription medicine abuse is increasingly recognized as a serious and growing problem in Nigeria. The perception, awareness and knowledge about PM abuse as a problem in the communities are high among the health worker respondents especially the doctors. However the attitude of the respondents towards early detection of PM abuse among their patients/clients is poor and discouraging. Lack of time especially by doctors, failure of clients to adhere to counsel by health workers, lack of continuing education and lack of necessary skills constitute barriers to counseling against PM abuse. On the other hand, occupation as a doctor or pharmacist, high educational level, working as government employee and female gender are all significantly predictive of good knowledge and positive attitude towards PM abuse.

\section{Recommendation}

1) Early intervention: Early intervention is meant to provide doctors and other health care professional with the necessary tools to detect PM abuse in its early stages. Additionally, information gathered can further help discover trends and figure out how to better funnel resources into PM abuse prevention.

2) Capacity building: All health workers especially non doctors and the less educated ones in the private sector must be made to mandatorily undergo regular trainings on PM abuse. To increase accessibility to such trainings, they could be organized at the trade union levels and then invite qualified resource persons to conduct the trainings.

3) Education is an important element of prescription medicine abuse prevention. Education and knowledge go beyond spreading the word about the dangers of using prescription drugs for non-medical purposes. Accumulated data on PM abuse should be analyzed to provide trend information to health care professionals and to the public. This can help local prevention programs pinpoint specific problems and decide where the most effective use of resources would be.

4) Public health initiatives: In addition to disseminating information, the government should be interested in taking an active role in creating public health initiatives that can reduce PM abuse. Data gathered can be used by states to develop appropriate laws and set up programs that can help prevent abuse. Public health initiatives can also provide appropriate monitoring through pharmacies and other health care professionals.

5) Law enforcement: Prescription drug monitoring programs should be designed to help law enforcement officials. Databases should be set up to help with information and evidence gathering. Illegal activities associated with prescription drug abuse can be tracked and prosecuted, when appropriate. This can be a deterrent for some when it comes to PM abuse, and it can encourage practitioners to be more conscientious about prescribing drugs to their patients. 


\section{Ethical Approval}

Ethical approval for the study was obtained from Research Ethics Committee, Nnamdi Azikiwe University Teaching Hospital (NAUTH), Nnewi, Nigeria. Permission was obtained from the pharmacies, the pharmacists', medical doctors' and licensed patent medicines vendors (chemical sellers)' associations. Verbal consent was obtained from study participants and they were informed that participation is voluntary - they were free to withdraw at any stage without any unpleasant consequences. All information was handled with confidentiality.

\section{Dissemination of Findings}

Findings have been prepared as manuscripts to be published in relevant scientific journal and will also be presented in a conference. Reports will be delivered to the leaders of the three associations, and appropriate health authority in Nigeria, with recommendations based on the study findings.

\section{Conflict of Interest}

The authors hereby declare that they have no conflict of interest in this research.

\section{Funding}

Personal income was used to fund this study—-there was no external source of funding.

\section{References}

[1] NIDA (2013) Drug Facts: Prescription and Over-the-Counter Medications. http://www.drugabuse.gov/publications/drugfacts/prescription-over-counter-medications

[2] Substance Abuse and Mental Health Services Administration (2011) Results from the 2010 National Survey on Drug Use and Health: Summary of National Findings, NSDUH Series H-41, HHS Publication No. (SMA) 11-4658. Substance Abuse and Mental Health Services Administration, Rockville. http://store.samhsa.gov/home

[3] National Survey on Drug Use and Health (2004) Characteristics of Primary Prescription and OTC Treatment Admissions: 2002. Office of Applied Studies, Substance Abuse and Mental Health Services Administration, Washington DC.

[4] Orhii, P. (2012) Prescription of Medicines in Nigeria...Abuse and implications for the Health of Nigerians’ A Presentation by Director General (NAFDAC) at the Physicians Week 2012 organized by Nigerian Medical Organization (NMA) Oyo State Branch, 23rd October 2012.

[5] Drug Abuse Warning Network (2006) Emergency Department Visits Involving ADHD Stimulant Medications. Office of Applied Studies, Substance Abuse and Mental Health Services Administration, Washington DC.

[6] Lessenger, J.E. and Feinberg, S.D. (2008) Abuse of Prescription and Over-the-Counter Medications. Journal of the American Board of Family Medicine, 21, 45-54. http://dx.doi.org/10.3122/jabfm.2008.01.070071

[7] NIDA (2011) Research Report Series: Prescription Drugs: Abuse and Addiction. www.erikbohlin.net/Handouts/personality...of_addiction.htm

[8] Onyeka, I.N., Uosukainen, H., Korhonen, M.J., Beynon, C., Bell, J.S., Rönkainen, K., Föhr, J., Tiihonen, J. and Kauhanen, J. (2012) Sociodemographic Characteristics and Drug Abuse Patterns of Treatment-Seeking Illicit Drug Abusers in Finland, 1997-2008: The Huuti Study. Journal of Addictive Diseases, 31, 350-362. http://dx.doi.org/10.1080/10550887.2012.735563

[9] McCabe, S.E. and Boyd, J.C. (2005) Sources of Prescription Drugs for Illicit Use. Addictive Behaviors, 30, $1342-1350$. http://dx.doi.org/10.1016/j.addbeh.2005.01.012

[10] Gianutsos, G. (2009) Prescription Drug Abuse: Strategies to Reduce Diversion. http://www.uspharmacist.com/continuing_education/ceviewtest/lessonid/106448

[11] Lafferty, L., Hunter, T.S. and Marsh, W.A. (2006) Knowledge, Attitudes, and Practices of Pharmacists Concerning Prescription Drug Abuse. Journal of Psychoactive Drugs, 38, 229-232. http://dx.doi.org/10.1080/02791072.2006.10399848

[12] Oshikoya, K.A. and Alli, A. (2006) Perception of Drug Abuse amongst Nigerian Undergraduates. World Journal of Medical Sciences, 1, 133-139.

[13] Pallant, J. (2010) SPSS Survival Manual. 4th Edition, McGraw-Hill, Berkshire.

[14] Partnership for a Drug Free America’s Website on Signs of Drug Abuse.

http://www.theantidrug.com/drug-information 
[15] Symptoms and Signs of Drug Abuse. http://drugabuse.com/library/symptoms-and-signs-of-drug-abuse

[16] National Institute on Drug Abuse. The Science of Drug Abuse and Addiction. www.drugabuse.gov/publications/drugs-brains-behavior

[17] Greater Good: The Science of a Meaningful Life. www.addme.com/reports/greatergood.berkeley.edu

[18] Kleinman, A. (2013) From Illness as Culture to Caregiving as Moral Experience. New England Journal of Medicine, 368, 1376-1377. http://dx.doi.org/10.1056/NEJMp1300678

[19] Kelley, J.M., Kraft-Todd, G., Schapira, L., Kossowsky, J. and Riess, H. (2014) The Influence of the Patient-Clinician Relationship on Healthcare Outcomes: A Systematic Review and Meta-Analysis of Randomized Controlled Trials. PLoS ONE, 9, e101191. http://dx.doi.org/10.1371/journal.pone.0094207

[20] University of Southern California School of Pharmacy Committee on Curriculum Development. http://pharmacyschool.usc.edu/

[21] Africapedia; Creating the Best Source of Facts and Trends on Africa. www.africapedia.com/DOCTOR-TO-PATIENT-RATIO-IN-AFRICA

[22] Fasinu, P. (2008) Between Doctors and Pharmacists in Nigeria and the Attendant Health Consequences. NigeriaWorld, Feature Article. 